\title{
Rural Lifestyle in Vietnam - Values and Drawbacks
}

\author{
Cao Thi Sinh \\ PhD, Hanoi National University of Education, Viet Nam
}

\begin{abstract}
The rural Lifestyle in Vietnam was born from a small, fragmented, outdated agricultural economy that existed for thousands of years. The lifestyle of small farmers still exists boldly, present in all strata of the population in Vietnam today. This lifestyle, in addition to its positive values, also has negative aspects, which greatly affect the establishment of the principles of living and working according to the law; is a major obstacle in building and perfecting the socialist rule-of-law state; building and developing an advanced culture imbued with national identity in Vietnam today. The article focuses on analyzing and clarifying "The basic characteristic of the Rural Lifestyle in Vietnam - Values and Drawbacks".
\end{abstract}

Keywords: Lifestyle, small farmers, values, limitations, Vietnam.

DOI: $10.7176 / \mathrm{JPCR} / 53-02$

Publication date: April $30^{\text {th }} 2021$

\section{Introduction}

The rural lifestyle in Vietnam was born from a small, fragmented, outdated agricultural economy, existed for thousands of years, the main labor force in society was human. Farmers. That production has not been completely erased. The rural lifestyle still exists boldly, present in all strata of the population, especially in our country's peasants. This lifestyle, in addition to its positive aspects, also has negative aspects, which significantly affect the establishment of principles of living and working according to the law; is a major obstacle in building and perfecting a socialist ruleof-law state; building and developing an advanced culture imbued with national identity in Vietnam. Therefore, the study of the basic characteristics of the small farming lifestyle in Vietnam in order to identify the positive and negative values, thereby finding suitable solutions to promote positive values and To overcome and limit the negative aspects of the Vietnamese micro-farming lifestyle is necessary, especially in the current context of globalization and international integration. Therefore, this article focuses on analyzing and clarifying: "Basic characteristics of the rural lifestyle in Vietnam - Values and Drawbacks".

\section{Research Methods}

To clarify the basic characteristics of the rural lifestyle in Vietnam - Values and Drawbacks, we base on the methodology of dialectical materialism and historical materialism, together with the using basic research methods such as analysis - synthesis method, logical - historical method, interpretation - inductive method, comparison method, comparison, ... as well as inheritance of data. from published works of scientists.

\section{Research results}

The Vietnamese rural lifestyle includes the habits, customs, customs, behaviors and attitudes ... of small farmers, formed under the direct influence of the economy. small farming and living conditions in agriculture and rural areas, it shows the relationship between individuals and communities in social life. The cottage lifestyle includes the following basic features:

\section{1. Positive values of the Vietnamese small farm lifestyle}

\subsubsection{Tradition of patriotism, community solidarity, industrious work and optimism in life}

Love for the country is the sentiment that dominates the entire psychological life of Vietnamese farmers. That national love is always strong and is promoted regularly, continuously, throughout the thousands of years of history of the Vietnamese nation. The patriotism of the Vietnamese people in general and the peasants in particular was formed and developed in the unique circumstances of the country - a country that often struggles against natural disasters. always have to deal with invasive hazards. That love of the country has always been tested regularly since the beginning of history, associated with the process of building and defending the country of our nation. Therefore, it is a noble spirituality not only associated with consciousness but also closely related to human morality, with the human personality and dignity of Vietnamese people. Circumstances, production, daily life and struggle against foreign invaders of the Vietnamese nation have formed in the history of Vietnamese peasants in the sense of mastering the destiny of the nation and the country. . Building water and keeping water go hand in hand. Whenever the country is threatened by foreign invaders, the Vietnamese peasants' sense of controlling the national destiny comes first. No one can deny that patriotism is the greatest sentiment of the Vietnamese people, of the Vietnamese peasants, especially the patriotic sentiment that has risen to patriotism. Looking at the history of the nation, we can see that the Vietnamese people's love for the country is always bright at all times. 
The love for our homeland, along with the difficult and difficult life, struggling with the harsh nature, fighting against foreign invaders, has fostered for our people the tradition of solidarity, the " uniting the community ". Historical fact has proven that whenever the country is in danger, the spirit of solidarity and community cohesion creates the strength to help our people overcome all difficulties and challenges. It can be said that the tradition of solidarity and community cohesion are characteristic of the Vietnamese farmers' lifestyle in particular and the Vietnamese nation in general. The sustainable life of Vietnamese peasants cohesion is formed from production, fighting and building the homeland and the country. Derived from the daily life, in handling the village's common affairs such as production, combating natural disasters, fighting against the enemy and participating in the country's political affairs, all of the households. farmers have united, stick together. This is the basis to create the solidarity and solidarity of the community of Vietnamese farmers, because dyke building, flood prevention, irrigation work, flood prevention, storm damage prevention, crop damage the exchange of labor experiences, production, the fight against the enemy to keep the village, the country ... is something that a farmer, a family cannot do. Members, small-scale farming households in the village linked together to form one big family. From family to village and broader country. The village can be seen as the epitome of water. Vietnamese people in general and Vietnamese farmers in particular are very aware of the relationship between house - village - water. Therefore, for them, the village community activities with ethnic community activities, the country with the house, the village with the country, there is a close connection, there is unity with each other.

Due to the specific characteristics of the Vietnamese peasants living in villages and treating the village as a small society of wet rice cultivation, most of their activities, from labor, production to combat, from birth. cultural activities to daily life and lifestyle all bring bold imprints of the village community lifestyle. All their economic, political, social ... activities are associated with the village. For Vietnamese people, the village is a very close concept and also very sacred, because the village has the expansion of the family. In the history of Vietnamese villages in general, villages in the North in particular, the isolation and self-contained are very high. Historically, that seclusion and seclusion limited the village's development and left many negative consequences to this day. However, from the above reasons, it is impossible to deny the farmer's spirit of community solidarity. Because these narrow village communities, as mentioned above, are still the "middle ground", consolidating houses with the country, and individuals with the nation. The tradition of community solidarity and attachment of Vietnamese people in general and farmers in particular is more evident when the country faces an invasion. Because the country died, the house was dissolved, so in order to keep the country, they had to unite to fight the enemy to save the country, and to ignore all personal hatred for a common goal of national salvation. That is also the reason to explain why Vietnamese people have the spirit of passionate patriotism and community solidarity. Why in the traditional values, in Vietnamese people, the values of the community are always strengthened, priority compared to many other values. Talking about the way of life, the character of the Vietnamese farmer cannot help but mention the love of work, diligence and optimism in life. This is a common characteristic of the Vietnamese people, the Vietnamese people, in which the peasant is a typical example. Very early Vietnamese peasants have been the owners of an early developing agricultural civilization. Living on a narrow land, many natural disasters, many enemies, so the peasants already have a spirit of hard work and that spirit has been ingrained in their blood and flesh, forming a fine tradition. The socio-economic and cultural works that have been preserved from thousands of generations to the present are proof of the love of work, diligence and patience of the Vietnamese farmers. harsh natural disasters.

With agricultural production, production tools are mainly manual and outdated, so the productivity of labor in agriculture is very low. In times of droughts, storms, storms or diseases, it is easy to lose crops. Life is unstable, even precarious, famines often occur, from which arose the mentality of small farmers is very afraid of hunger. Therefore, more than anyone else understands that, if they do not work hard or be lazy in their work, they will go to poverty. Therefore, Vietnamese farmers are always diligently overcoming difficulties in labor and saving time and material possessions: "ability to pick up", "time is golden", "a golden inch of land" ... Although the natural conditions, living environment and production of small farmers are so difficult, but they are still optimistic, love life, love life. The small farmer has a very flexible lifestyle, round, long tube with high adaptability. In any difficult situation, Vietnamese people are not discouraged, but always have the will to rise. At the end of the tragedy of loss, one still thinks: "There are feathers, still buds, trees", "there are still people.

\subsubsection{Lifestyle that values people, respects emotions, values morality, respects honor, respects reputation, respects the elderly}

In agricultural production, in order to cope with natural disasters, enemy sabotage, and enemy attacks, people are very necessary and need many people. On the other hand, due to the lack of living conditions and difficulties, due to medical limitations and limited awareness in the care and protection of human health ..., the rural lifestyle respect human: "A man living in a pile of gold", "One face of man is equal to his face", he is highly appreciated to the absolute level: "One is a flower of the earth" ... Since then There was a mentality that attaches great importance to people in small farmers in particular, and Vietnamese people in general. Stemming 
from the tradition of community solidarity, at the same time due to the lack of material, the limitation of means in daily life, difficult times, tribulations, sickness, and great work ( getting married, building a house ...), the farmer often asks for help from neighbors and neighbors. Therefore, the farmer always behaves with affection, attaches importance to emotions in social relationships. Under different forms and degrees, emotions penetrate the whole farmer's life and activities from perception to action, from morality to lifestyle, from style to personality. . In the life of a small farmer, emotions directly dominate both thoughts and actions. That sentiment is also expressed in respect for the elderly (respectful), respect for talented people, respect for people with ethics, knowledge ... However, the relationship itself, behaves with love. This feeling of feeling and appreciation of this sentiment arose a feeling of fear of conflict, fear of fighting for righteousness, and a lack of democratic spirit among Vietnamese peasants. Traditional Vietnamese nation in general and farmers in particular always attach great importance to morality, think and act according to goodness. In most of the ancient villages of the remaining and studied villages, we see that farmers attach great importance to preserving personal morality, preserving the traditional culture of the village. commune and ethnicity. Vietnamese peasants living in villages and communes attach great importance to gratitude. Love is love, cherish each other. That means duties, responsibilities, and obligations together. They always emphasize the harmony between love and human obligations. The attachment between love and meaning has created a kind behavior. There, one can reconcile personal and family relationships, reason and emotions, responsibility and obligation to create a harmonious and stable life. That has balanced the balance of society; Although everything has been revolving, creating unpredictable changes, the life of a farmer for thousands of generations still creates its own peace and tranquility. The strength of the gratitude behavior is clearly shown in the very personal space of each person - that is, family. For that reason, in the formal education of feudal Vietnam, moral education is very important, "first-class ceremony, post-literacy" is very important, while in the family, moral education is considered content. basic, mostly. In the family, the generations of grandparents, parents always educate their children: "The torn paper must keep the margins" or: "Hungry, clean and fragrant"; "Hunger than a lifetime". Preserving the eternal moral tradition of parents, grandparents, ancestors - that is the human dignity. It is also an honor, is the way of life of the Vietnamese people.

Rural lifestyle live closely with people in their villages, lineages, and families; live for each other, for each other and follow each other. Therefore, they live by public opinion and behave themselves according to that opinion. Public opinion has created a reputation, a reputation and a reputation: "Buffalo die to skin, people die for reputation", "A hundred years of stelae are worn out / a thousand years of beer mouth remains inert". This creates a mentality of honor, considering honor is sacred in the small farmers. On the other hand, in the old social ladder, people with titles, positions, and the elderly are respected. Since then, there has been a mentality of respect for status, respect for reputation (honor), to have a name, to have a reputation in the village, in the commune, within the family and more broadly, for the country and the people. The ethnic minorities of the small farmers: "Being a boy living in heaven and earth / What must have a namen with mountains and rivers" (Nguyen Cong Tru). In this respect, we still see that the small farmer, although poor, still respects the scholar (the educated): "the first one, the second farmer", the meaning of the word: "A treasure of gold is not equal to a character". ...

\subsection{Some limitations of the Vietnamese small farm lifestyle}

\subsubsection{Small and fragmented production habits, a conservative lifestyle, based on experience, afraid of innovation}

Rural Vietnam before the August Revolution was a privately owned small-farm society. Each farmer household has one or a few plots of fields to grow, self-sufficient, and self-sufficient with their own products. Households who do not have land have to plow and hire to live. Due to the needs of production, the labor farmer knows the simple forms of cooperation, but the scale is very small, mainly seasonal and only sporadic a few families follow the alley. regularity, continuity. The issue of labor cooperation with a wider scale and high collective organization is a strange issue for small farmers. If the working conditions of production and natural improvement such as embankment of dykes, irrigation, fighting against foreign invaders ... have closely consolidated the community, in contrast, the characteristics of a small production base, fragmentation, scattering, separating the small farmers from each other. Every day, they do the same work, exist together, but there is little linkage, organic ties to each other. Living in a small village community, Vietnamese peasants have a close relationship in the style of family cohesion. The mentality of sticking to the village for peace of mind is also ingrained in each person. Over time, village institutions have strengthened this mentality. While the land is shrinking due to the natural increase in population, the cultivated land is shrinking due to being gradually converted to residential land, and for the construction of industrial works ... the land is smaller and smaller, fragmented, the production of small farmers is more and more difficult. At the same time, it is the production method of this separate and fragmented smallholder economy that has led to the thinking of the small farmer, which is also very sporadic, sporadic, without foresight, without war. drink. That way of thinking, together with 
the field, the plow further ties the farmer in the village of bamboo, is in peace with the vicious life, less organized, disciplined, alien to the thinking of civilization. industry, like stability, security, easy to fall into myopic psychology; habits are based on experience, difficult to absorb new things, afraid to innovate. Thereby leading to a behavior with a cluster of "lights in the house, the house is bright" or "a neighbor's house is on fire, so there is a lack of cooperation, sense of responsibility, and indifference to the community." Farmer department. This mentality is an inevitable consequence of low-level development of production. Until the end of the nineteenth century and early twentieth century, when the world entered the industrial civilization era, the countryside and Vietnamese peasants were still immersed in the small, fragmented and peanut production method. late, stagnant.

Vietnamese smallholder farmers are originally from the river, taking cultivation as their main labor. Their life and production depend a lot on nature, weather, climate ... Moreover, our country has a self-contained, pure agricultural production economy. This feature in turn dominates the closed state in social relations, in the way of thinking and looking at the small farmer. If in a modern society, production and market demand are two sides that have a positive impact on each other, in the traditional society of small farmers, the need to exchange and trade goods in the market has not. develope. Therefore, inevitably production also does not develop. For small farmers, they just need to ensure the needs of a minimum life and living. They do not have the need to explore and create new things, so the arising of the psychology of appreciating experience is inevitable. Therefore, their vision and thinking are also limited and not expanded. The small farmer lives and works according to the traditional customs, clinging to the old without daring to experiment with new ones. They are content with a life of frugality, stability, enough, little interest and not even interested in new things happening beyond their small scope of activities. From father to son, "they plow their land completely in the old rudimentary way of their fathers and resist all new with the inherent stubbornness of the slave of the custom. Over many lifetimes remains unchanged ". Therefore, over time, they became more and more conservative. The end result is that conservatism has led the farmer to become backward, too far behind the general progress of the whole society.

The rural lifestyle lives and works according to the traditional customs, clinging to the old without daring to experiment with new ones. They are content with a life of frugality, stability, enough, little interest and not even interested in new things happening beyond their small scope of activities. From father to son, "they plowed their land completely in the old rudimentary ways of their fathers and resisted all new with the inherent stubbornness of the slave of the past. Lifetime lives have not changed". Therefore, over time, they became more and more conservative. The end result is that conservatism has led the farmer to become backward, too far behind the general progress of the whole society. Thus, the production method of the small farm economy is separate, fragmented, the production is at the manual level, backward, so the conservative, empirical way of thinking, afraid of innovation have become a habit in the way. the farmer's life. They think, act, behave and feel everything according to that habit. This is a major limitation in the way of life of Vietnamese farmers, a hindrance to them in the process of opening up integration and international exchange for development.

\subsubsection{Narrow lifestyle, local interests, local, arbitrary, less disciplined, disciplined, not in the habit of respecting and obeying the law}

The characteristic of rural Vietnam, most notably the Northern Delta and Midlands is the small land ownership regime that dominates, family is the main economic unit, and production is fragmented. On the farmer's small land is a private sky that has tied them up in tight frameworks, by taking care of family life and personal interests. That is the source to arouse a narrow and beneficial lifestyle among Vietnamese small farmers. With the feature of having to fight against harsh natural disasters and violent foreign enemies, the ethnic cohesion of the Vietnamese community is very high. Besides the positive side of strengthening solidarity, working together and fighting together, it also has certain limitations, full of contradictions within the farmer himself. Just as Professor Ha Van Tan, when discussing the dialectic of the village tradition, on the community and its limitations reiterated the idea: "Someone said very well that, in this period, water but there is a village, and thanks to the village, in the end there is water. But as for the village, there is still the community of the village and the limitations of the village" ${ }^{1}$. That is the duality of dialectical unification but full of contradictions that exist within the Vietnamese farmers themselves. So also a human being, but at this moment, the sense of community, altruism, mutuality, mutual love, directing people to the greatness, at other times, in other places, they are trying very small, local interests, much local.

It is that inconsistency that makes Vietnamese farmers look far away but still close and lofty but still not lift themselves up, wide but narrow, very affectionate but sometimes full of strangers. People kept fighting and dividing rice, saying hello to each other for rice, 'selling rice fields and suing the shore' ... ${ }^{2}$ On the other hand, the fragmented production method, the dispersed production method, the traditional cultivation method inherited

\footnotetext{
${ }^{1}$ Citing Nguyen Quang Du (1994), The sense of peasantry among cadres and party members in rural North Vietnam - the main features, Thesis of Philosophy PTS thesis, Hanoi, p.53, 54

${ }^{2}$ Citing Nguyen Quang Du (1994), The consciousness of peasantry among cadres and party members in rural North Vietnam - the main features, Philosophy Deputy Doctoral Dissertation, Hanoi, p.53, 54.
} 
from generation to generation, so the labor productivity is low, the product is only enough to meet the consumption needs of the village. the farmer's small family, family and community. That has dominated their relationships, making these relationships just stop within families, relatives, and villages. In addition, underdevelopment of infrastructure and means of transport, along with precarious and impoverished lives, have hindered their relationship from expanding. These are favorable conditions for the birth and nurturing of the local local lifestyle of Vietnamese small farmers. They are like the French peasants of the mid-nineteenth century, surnames "...never go beyond the closest local relations, and from the narrow local horizon attached to those relationships" (4). With myopia within the scope of small private owners, Vietnamese small farmers cannot see far, look wide, only see immediate benefits, local benefits, do not see long-term benefits, benefits. total. On the other hand, people living in each region and region of Vietnam have their own customs, habits, lifestyles, personalities and psychology, so harmony is not always favorable. In many cases, there is a difference between commune and commune, and province is separate from another. Even within one village, one village is separate from another, and one family line is also separate from another. This is a good land for a local lifestyle to arise and develop. And also, there appeared the mentality of jealousy, narrow-mindedness, clinging ... in each group of small peasant communities such as family, relatives, villages ... Gradually, narrow-mindedness. The locality has become a distinct feature in the lifestyle of Vietnamese small farmers. It governs their daily behavior, attitudes, and behaviors. In some cases, they take care of the narrow interests of family, relatives, villages ... but forget the interests of the nation, the nation. That way of production by Vietnamese small farmers has resulted in them being unfamiliar with the law. If in capitalist countries with early developing commodity economies, farmers do business within a certain legal framework. Farmers can not arbitrarily, disregard the law and the laws of the market, so they will be paid by bankruptcy or loss. And Vietnamese small-scale farmers produce spontaneously, with the aim of being self-sufficient, self-sufficient and self-sufficient. They produce for me, for me. This creates arbitrary, lack of discipline, discipline, and lack of habit of living and working under the law of Vietnamese small farmers.

Moreover, stemming from the country's historical circumstances, before the Northern colonial period, Vietnamese small-scale farmers used to appreciate and live according to the "village custom". Villagers abide by the regulations of the "village custom" voluntarily and seriously. They live according to village custom, custom, custom, less familiar with the law. They are just afraid of the village's law, public opinion, but not the law, and even despise the law "the king's rule loses the village's rule". When the feudal North began to colonize our country, they brought in a harsh legal system to easily rule. Given the nature of that legal system, from the beginning, the Vietnamese people were hostile and opposed to the law, not subject to the law; take it as a manifestation of aggression, a foreign culture. On the other hand, our country has not experienced bourgeois democracy. Bourgeois democracy has its limitations, but nonetheless it also contributes to individual affirmation, establishing the category of "citizenship", promoting law, discipline as well as a series of other social relations. In such a society, the sense of responsibility, rights and obligations of citizens towards society is very clear. Of course, the habit of arbitrary, unscrupulousness, and disregard for the law will not have favorable conditions for development. That greatly affects the building of awareness of compliance and respect for the law of the Vietnamese people in the renovation cause of our country today. Thus, the narrow lifestyle, self-interest, local locality, arbitrary habits, lack of discipline, discipline, and disregard for the law of small farmers have a great impact, not only too much. development of each individual and community, but also affects each region, region and nation. It inhibits the expansion of the visibility and relationships of small farmers, inhibits the progress of the rural community and the social community. Thus, the characteristics of the Vietnamese micro-farming lifestyle are manifested in a very diverse and abundant way with many nuances: the bad, the good, the positive, the negative, intertwined, intertwined. Besides patriotism, community solidarity, love of labor, industriousness, thrift, optimism in life; respect for people, respect for emotions, respect for morality, respect for honor, respect for reputation ..., in Vietnamese small farmers, there are still small and fragmented production habits, conservative and experienced lifestyles. narrow-minded, self-interested, local, arbitrary, less disciplined, disciplined, more dignified than law, more serious than reason ... That is duality that is both unified and contradictory in the peasant lifestyle. Vietnam. The positive characteristics and good things in the Vietnamese small-farm lifestyle reflect the fine cultural traditions of the nation that are molded, selected and inherited from generation to generation, contributing to creates the image of Vietnamese people, has the effect of promoting social development and progress. This is also one of the sources of the strength of Vietnam throughout history.

\subsection{The reason exists a number of limitations of the current small farming lifestyle in Vietnam}

The spiritual life, human consciousness is not the product of the subjective will of an individual or a group of people but the product of society - history, conditioned by objective conditions, it affected and influenced by living conditions, labor, "" material "activities of the society. Affirming the origin of human consciousness

\footnotetext{
${ }^{1}$ Mark and Ph. Angghen (1993), Complete Works, Volume 7, National Politics Publishing House, Hanoi, p. 459.
} 
formation, Mark - Ph.ngghen emphasized: it is not human consciousness that determines their existence; on the contrary, their social existence determines their consciousness. But, although our country has had many changes, especially great economic changes, the limitations and negatives of the small farming lifestyle are not only lost but still exist, because probably:

Firstly, the small farming lifestyle was formed and existed under the influence of a variety of factors (economy, society, history and culture ...) linked together through thousands of years of history, thus it is inheritance, becomes a habit, a habit; Therefore, it is powerful as well as very conservative and inert.

Second, the backward, self-sufficient, self-sufficient smallholder economy ... is the basis for creating a small-farm lifestyle. Currently, although our country's economy is a socialist-oriented market economy, basically, the production method of Vietnamese farmers is still mainly small production with rudimentary tools. . On the other hand, the market economy is a very new issue compared to the thousands of years history of the selfsufficient agricultural economy in our country. opportunities for negative socio-economic problems arise and are at risk of exacerbation. It is a fertile ground for the peasant's negative habits, customs, states and psychological needs to revive.

Third, very important changes in agriculture and rural areas, especially the policy of bringing the agricultural economy under the socialist-oriented market mechanism, bringing agriculture, peasants, and rural communities. quickly enter the industrialization, socio-economic modernization of the whole country, rapidly changing the socio-economic face of rural areas, strongly affecting farmers and giving rise to, new manifestations of their lifestyles appeared. However, these manifestations have not had strong pervasive power in each Vietnamese people in general and farmers in particular. Therefore, the limitations in the rural lifestyle are still land to survive and develop.

Fourthly, although the urbanization rate of Vietnam is relatively fast, more than $70 \%$ of the population still lives in rural areas. On the other hand, the outstanding feature of our culture is the village culture, so there are many close and intertwined relationships between urban and rural people, many strong relationships exist. Small-scale psychology such as kinship, lineages, family ... Moreover, the restoration of cultural relics such as temples, pagodas, shrines ... is associated with religious activities taking place in recent years, Besides the positive, there are also limitations from the old customs and practices. All of these have created conditions and nourishing environment for the negative aspects of the peasant lifestyle to revive and develop ... This explains why the negative aspects of the small farm lifestyle are not only not lost. but also develops stronger when the physical and mental life conditions are improved more and more.

Fifth, because our mechanisms, policies and laws are not synchronous, there are still gaps, the enforcement of the law is not strict, so it has not created a deterrent to negative phenomena such as illegal business. , disregard for discipline, water magic ... This creates more conditions to nurture negative psychological features in the small farm lifestyle to exist and develop.

Sixthly, a large part of farmers lack and weak knowledge in fields such as: economics, law, society ... are not adaptive, dynamic, and sensitive to activities in the market economy. current market, with the trend of globalization and integration in the world.

\section{Conclude}

The Vietnamese micro-farming lifestyle is a very complex, varied phenomenon, the bad, the good, the positive, the negative, intertwined. Besides the positive aspects such as patriotism, community solidarity, love of work, diligence, optimism in life; respect for people, affection, respect for morality, respect for honor ..., the peasant lifestyle also has negative and limited aspects: small production habits, fragmentation, conservative character, Speaking from experience; narrow-mindedness, self-interest, local, arbitrary, less disciplined, disciplined, more serious than moral, more important than the law ... In the process of industrialization, modernization and international integration, characteristics of the small farm lifestyle have changed. The positive aspects in the Vietnamese micro-farming lifestyle are that the traditional cultural values of the nation continue to be inherited and promoted. The limitations, negatives, and evils in the Vietnamese micro-farming lifestyle still have conditions to survive and nurture; some new manifestations in the exotic lifestyle have been imported .... That shows the complicated trend of change in the Vietnamese micro-farming lifestyle. In order to promote the positive aspects, at the same time overcoming the shortcomings of the peasant lifestyle, selectively and rationally absorb the lifestyle of the ethnic groups in the world, on the basis of preserving the identity of the document. Vietnam's nationalization needs synchronous solutions to bring into play the values and gradually overcome the limitations and negatives in the mentality of Vietnamese small farmers. This system of solutions we will discuss in another article.

\section{References}

1. Toan Anh (1992), Old Glutton - Vietnamese Village, Ho Chi Minh City Publishing House.

2. Phan Ke Binh (1990), Vietnamese customs, Ho Chi Minh City Publishing House. 
3. Phan Dai Doan (1992), Vietnam Village - Some Socio-Economic Issues, Social Science Publishing House, Hanoi.

4. Nguyen Quang Du (1994), The consciousness of peasantry among cadres and party members in rural North Vietnam - the main characteristics, Philosophy PTS thesis, Hanoi.

5. Tran Van Giau (1980), Traditional spiritual values of the Vietnamese nation, Social Science Publishing House, Hanoi.

6. Phan Huy Le, Vu Minh Giang (editor) (1994), Traditional values and the current Vietnamese people, Volume 1, Social Sciences Publishing House, Hanoi.

7. Phan Huy Le, Vu Minh Giang (editor) (1996), Traditional values and the current Vietnamese people, Volume 2, Social Science Publishing House, Hanoi.

8. C. Mark and Ph. Angghen (1993), Complete Works, Volume 2, Political publishing house, Hanoi.

9. C. Mark and Ph. Angghen (1993), Complete Works, Volume 7, Political publishing house, Hanoi.

10. Ho Chi Minh (1995), Complete Works, Volume 6, National political publishing house, Hanoi.

11. Ho Chi Minh (1996), Complete Works, Volume 9, National political publishing house, Hanoi.

12. Pham Xuan Nam (1998), Culture for Development, Political publishing house, Hanoi.

13. Phan Ngoc (1998), Vietnamese Cultural Identity, Culture - Information Publishing House, Hanoi.

14. Nguyen Hong Phong (1963), Understanding the national character, Social Science Publishing House, Hanoi.

15. Tran Dang Sinh and Nguyen Chu Sam (Co-Editors) (2014), Dao is a person in Vietnamese culture, Political Theory Publishing House.

16. Vo Van Thang (2005), Inheriting and promoting the traditional cultural values of the nation in the construction of a lifestyle in Vietnam today, Ph.D. Thesis in Philosophy, Hanoi.

17. Tran Ngoc Them (1998), Vietnam Cultural Foundation, Education Publishing House, Hanoi.

18. Institute of History (1977), Rural Vietnam in History, Volume 1, Social Science Publishing House, Hanoi.

19. Institute of History (1979), Rural Vietnam in History, Volume 2, Social Science Publishing House, Hanoi.

20. Institute of History (1990), Farmers and Rural Vietnam in modern times, Volume 1, Social Science Publishing House, Hanoi.

21. Institute of History (1993), Farmers and Rural Vietnam in modern times, Volume 2, Social Science Publishing House, Hanoi.

22. Tran Quoc Vuong (editor) (2000), Vietnam Cultural Foundation, Education Publishing House. 